\title{
Contraception module: innovative strategies to improve students learning
}

\author{
Jayasree Manivasakan $^{1 *}$, Bupathy Arunasolamme ${ }^{2}$
}

\author{
${ }^{1}$ Department of Obstetrics \& Gynaecology, Sri Manakula Vinayagar Medical College and Hospital, \\ Kalitheerthalkuppam, Madagadipet, Pondicherry, India \\ ${ }^{2}$ Department of Obstetrics \& Gynaecology, Indira Gandhi Medical College and Research Institute, Pondicherry, India
}

Received: 18 August 2015

Accepted: 02 September 2015

\section{*Correspondence:}

Dr. Jayasree Manivasakan,

E-mail: jayasreevyshali@gmail.com

Copyright: ( ) the author(s), publisher and licensee Medip Academy. This is an open-access article distributed under the terms of the Creative Commons Attribution Non-Commercial License, which permits unrestricted non-commercial use, distribution, and reproduction in any medium, provided the original work is properly cited.

\begin{abstract}
Background: Male and female contraception is taught in MBBS as lectures and tutorials. But the amount of information the student has to digest is more and topic is considered by many students as uninteresting. To obtain student feedback on different teaching strategies used in the module for further improvement.

Methods: The students attended didactic lectures in their sixth semester and modular teaching in the eighth semester. Pre-test was given before the problem based discussions in the eighth semester. Video clippings, role play, small group discussions were used to teach contraception. In Post-test, multiple choice questions were projected on the screen one by one and the answers were discussed. The students were given feedback forms and asked to comment on the teaching learning method.

Results: The pre-test scores and the post-test scores were analysed using ANOVA and the increase in variance in the score is significant with $95 \%$ confidence interval. From the observations in the feedback form, it is evident that the students want more roles for themselves in the learning process.

Conclusions: Modular teaching can be made very interesting both for the teacher and the student if the modular teaching is made more flexible and simple with lot of imagination and innovation.
\end{abstract}

Keywords: Contraception, Modular teaching, Feedback

\section{INTRODUCTION}

Male and female contraception is taught in MBBS as lectures and tutorials. But the amount of information the student has to digest is more and topic is considered by many students as uninteresting. Module on contraception is being taught in institutes involving several departments like OBGY, surgery, pharmacology, physiology, social medicine etc., if there is not much co-ordination among departments there will be overlap of information and no true integration. Pre-test and post-test become a ritual where the test results are announced and forgotten. The contents of a typical module on contraception and the departments involved are as follows:
1. Physiology of ovulation and spermatogenesisPhysiology.

2. Population dynamics and counseling- preventive medicine.

3. Barrier methods and IUCD- OBGY.

4. Hormonal and non-hormonal methodspharmacology.

5. Surgical methods in female- OBGY.

6. Surgical and nonsurgical methods in male- surgery.

Considering the practical difficulties mentioned above and to make the module more effective and interesting to the students, the Department of OBGY brought in some modifications. 
This study was done to obtain student feedback on different teaching strategies used in the module for further improvement of the module.

\section{METHODS}

All the students of 2008 batch (101/150) of Sri Manakula Vinayagar Medical College and Hospital who had proceeded to sixth semester attended didactic lectures about contraception and attended modular teaching in the eighth semester. Pre-test was given before the case based discussions in the eighth semester.

First, for better coordination and effective screening of teaching material, the number of departments was reduced from 5 to 3 involving only OBGY, pharmacology and social medicine.

Next, the speakers were allowed only 15 to 20 minutes for each topic and the rest 10 minutes was given for video clippings. Video clippings included procedures like IUCD insertion, tubal sterilization methods and vasectomy with running commentaries.

Thirdly, one full session was allotted for role play by the students regarding counselling, selection of contraceptives in different clinical and social situations which was facilitated by a faculty.

Finally, students were given group tasks on different clinical situations and asked to make a brief presentation followed by discussion. The following are a few problems given for group task/role play:

1. A married woman comes to the clinic and says that she is two months pregnant in spite of her husband using condoms and that her husband is suspecting her integrity How will you talk to the husband and convince him?

2. A 24 year old woman, para2, had copper $\mathrm{T}$ insertion 2 months back. She comes to the clinic with 2 months of amenorrhea. She also says that she is not able to feel the thread in the vagina. What are the possibilities and how will you tackle the problem?

3. A woman comes to the clinic crying and tells you that her husband had undergone vasectomy 3 months back and now she is 2 months pregnant. Her husband is suspecting her fidelity. How will you settle the problem?

4. A newly married couple comes for contraceptive advice to postpone pregnancy for 2 years. The wife is working in a chemical factory on contract for 2 years. How will you counsel the couple?

5. A newly married woman who was started on OC pills had forgotten to take the pills for 2 days in between. After finishing the course, her periods got delayed by 10 days. How will you manage her problem?

6. A business on frequent tours visited his wife unexpectedly. The wife was on 16 the day of her menstrual cycle when they had coitus. What are the choices available to the couple to prevent pregnancy?

7. A woman with one living child attends the family planning clinic for copper $\mathrm{T}$ insertion. She gives history of irregular cycles with increased flow. Her hemoglobin is $7.5 \mathrm{~g}$. How will you counsel her?

8. A para 1, who delivered 4 weeks ago wants contraception. How will you advise her?

9. A newly married couple comes for counseling regarding family planning. They are against using condoms, IUCD and drugs on religious grounds. They definitely do not want any child for 2 years. How you help them choose the best method?

10. A commercial sex worker comes to the clinic and wants copper $\mathrm{T}$ insertion. How will you advise her?

11. A 35 year old woman, who is a known diabetic for the past 5 years, has delivered recently. She does not want the second child for 4 years at least. How will you advise her?

12. A mother brings her mentally retarded 17 year old daughter to the OPD. She says that her daughter is being sexually exploited by unknown persons and she had to undergo MTP twice. She wants tubal sterilization to be done for her daughter. Will you do it?

13. A para 1, was on OC pills for the past 6 months. She developed pulmonary tuberculosis and was started on ATT 3 months back. Now she is 2 months pregnant. How will you tackle the problem?

After the module of contraception was over, post-test was conducted. In post-test, the multiple choice questions were projected on the screen one by one and the answers were discussed. The students were allowed to score themselves and compare with the pretest results. The students were also given feedback forms with open ended questions to comment on the content of the lectures, time management, student interaction, videos and animations, role play by the students and pre and post tests and any other comments.

\section{RESULTS}

Out of 101 students, 78 students responded in the feedback form. From the observations, it is evident that the students have stressed on four important aspects:

1. Interaction in the form of group discussion.

2. Videos wherever possible.

3. Role play by the students.

4. Discussion of pretest questions at the end instead of posttest.

It is obvious that the students want more roles for themselves in the learning process; they do not relish the conventional type of modular teaching and more rigid type of pre and posttests. 
Table 1: Feedback Comments.

\begin{tabular}{|c|c|c|}
\hline & COMMENTS & NO. \\
\hline 1 & $\begin{array}{l}\text { Interaction in the form of group discussion } \\
\text { was good }\end{array}$ & 19 \\
\hline 2 & $\begin{array}{l}\text { Want more problem based discussion than } \\
\text { lectures }\end{array}$ & 2 \\
\hline 3 & Lectures were short and sweet & 4 \\
\hline 4 & Some lectures were lengthy & 4 \\
\hline 5 & Role play was good & 19 \\
\hline 6 & Videos were good & 33 \\
\hline 7 & Want more video/animation & 2 \\
\hline 8 & $\begin{array}{l}\text { Discuss the questions instead of } \\
\text { conducting post test }\end{array}$ & 17 \\
\hline 9 & Time management was good & 6 \\
\hline 10 & Shorten the overall time everyday & 5 \\
\hline
\end{tabular}

Table 2: Pre-test and post-test scores.

\begin{tabular}{|lll|}
\hline Marks & $\begin{array}{l}\text { No. of students } \\
\text { pretest }\end{array}$ & $\begin{array}{l}\text { No. of students } \\
\text { posttest }\end{array}$ \\
\hline 5 & - & 1 \\
\hline 6 & - & - \\
\hline 7 & - & 1 \\
\hline 8 & 6 & 4 \\
\hline 9 & 4 & 4 \\
\hline 10 & 2 & 2 \\
\hline 11 & 8 & 2 \\
\hline 12 & 4 & 6 \\
\hline 13 & 12 & 6 \\
\hline 14 & 4 & 4 \\
\hline 15 & 4 & 4 \\
\hline 16 & 8 & - \\
\hline 17 & - & 6 \\
\hline 18 & - & 4 \\
\hline 19 & - & 4 \\
\hline 20 & - & 2 \\
\hline 21 & & \\
\hline
\end{tabular}

To maintain objectivity, we conducted posttest after three months and the results tabulated below. Only fifty two students participated in the post test because the batch was broken for different clinical postings. No student scored less than 5 or more than 21 marks. The average score per student was $12.30+/-2.47$ (pretest) and $13.85+/-$ 4.03 (posttest) since the number of students below $40 \%$ (below 10 marks) is the same in both the tests (10students), we can assume that the variance is applicable to students scoring $40 \%$ and above. For these students the increase is 1.5 marks. i.e., 1.55+/-1.50 (range 0.05-3.05). Using ANOVA, we can conclude that the increase in variance (1.55) is significant by $95 \%$ confidence interval. Thus the range of effect the test has had is from no improvement to an improvement by one eighth of one student's previous score (no improvement to +3 out of 25 marks.

\section{DISCUSSION}

To achieve the national goal of population control the undergraduate student's skills should be developed. According to Medical council of India regulations on graduate medical education, the instruction relating to family welfare planning education should be given in an integrated manner by the department of Community Medicine, Internal Medicine, Psychiatry, Paediatrics and Surgery in close association with Department of Obstetrics and Gynaecology.

It is estimated that $78 \%$ of pregnancies are unplanned and $25 \%$ are definitely unwanted in India. To motivate the couples to use contraception and to decrease the rate of unplanned pregnancies information should be given at every visit to the health services. In a recent study on student's knowledge and attitude regarding contraception even though the students have positive attitude they lack correct knowledge. ${ }^{1}$ Students in US and Canada have also reported that pregnancy physiology and STIs/HIV was given higher coverage in contrast to contraceptive methods and elective abortion procedures. ${ }^{2}$

Attention span of an adult is 15-20 minutes. The instructional strategies has to be changed to increase this time span. ${ }^{3}$ In a study in Pakistan, the endocrinology and reproduction module was delivered using variety of learning strategies. ${ }^{4}$ Case based discussion and large group discussion were the equally favoured method of learning strategy by this group of students. Group discussions and role plays were more favoured by our students than didactic lectures and problem solving sessions. But they showed more interest in video demonstrations of contraceptives technique.

In problem-solving teaching, the staff set the problems (case history problems in a primarily lecture- based format), and students attempt to resolve them using previously taught curricular content. In a case based learning in the department of biochemistry, the attitude survey of the students showed that this module promoted active independent learning, development of critical thinking and communication skills. ${ }^{5}$ But in our study only 2 students wanted more case based learning. In a comparison between traditional lectures and small group discussions of cases and practical activities for teaching obstetrics and gynaecology, students gave higher rating to clarity of classes and lecturers teaching ability and punctuality for small group discussions which was statistically significant ${ }^{6}$. Since the feedback form given to 
our students was open ended and qualitative in nature we could not assess the significance. In dermatology where multiple case methods were used as an adjunct to classic lecture based curricula the students have opined that case method helps them to manage large course content and the discussions clarify their thoughts. ${ }^{7}$ In our study also the students have given positive comments to discussions.

Role plays improve communication skills in students where traditional methods of instruction are not useful and they are rich in cognitive material. Role plays have been used in other studies to impart breaking bad news, ${ }^{8}$ and to teach students to communicate with simulated patients and provide drug and non-drug information. ${ }^{9,10}$ In our module students were asked to do a role play on counselling couples to stress the cafeteria approach of counselling for contraception. The students were asked to enact two scenarios. One was a newly married couple requiring contraception and the other was a couple who wanted long term contraception after two children. It was a hot seat type of role-play, in which the facilitator balanced attention between student in the hot seat and the observing group.

Visual images along with verbal instructions lead to more knowledge retention when compared to verbal instructions or visual images alone. ${ }^{11}$ Students wanted more videos in their lecture because they help them to sustain their interest and visualize the concepts and understand better. When videos were incorporated along with lectures students have given feedback that they want more videos in our study.

Testing after a training course helps in increasing learning outcome. ${ }^{12}$ Assessment which invites discussion from the student regarding a particular topic might be one of the good methods. ${ }^{13}$ In our study instead of conducting post-test the multiple choice questions were projected and the questions were discussed with the students. This was comparable to a study where multiple choice questions was used as teaching learning tool in addition to assessment method and students gave positive comments that this method increased their interest and made them gain confidence in the subject. ${ }^{14}$ When patient oriented problem solving system was used to teach haematology, the students post test score was significantly higher than the group of students taught by traditional lectures. ${ }^{15}$ Students taught by case methods gave good rating to the quality of tests than the group of students taught by lectures in Brazil. ${ }^{6}$ The post test score was statistically higher than the pre-test score which shows that the new method help the students to study with greater interest and satisfaction in our study.

Limitations of the study: This study evaluates only one module in department of Obstetrics and gynaecology. It was carried out among only one batch of students and the sample size was small. Comparison of traditional teaching and integrated teaching methods between two groups was not done.

\section{CONCLUSIONS}

If more innovative methods were to be incorporated in teaching learning process of a module, it will be become more interesting both for the teacher and the students.

Funding: No funding sources

Conflict of interest: None declared

Ethical approval: The study was approved by the Institutional Ethics Committee

\section{REFERENCES}

1. Giri PA, Bangal VB, Phalke DB. Knowledge and Attitude of Medical Undergraduate, Interns and Postgraduate Students in India towards Emergency Contraception N Am J Med Sci. 2013;5(1):37-40.

2. Steinauer J, LaRochelle F, Rowh M, Backus L, Sandahl Y, Foster A. First impressions: what are preclinical medical students in the US and Canada learning about sexual and reproductive health? Contraception. 2009;80(1):74-80.

3. Goodman BE, Koster KL, Redinius PL. Comparing biology majors from large lecture classes with TAfacilitated laboratories to those from small lecture classes with faculty-facilitated laboratories. Adv Physiol Educ. 2005;29:112-7.

4. Ghayur S, Rafi S, Khan AH, Ahmad RN, Iqbal M.. Delivering endocrinology and reproduction in an integrated modular curriculum. J Pak Med Assoc. 2012;62(9):937-41.

5. Surapaneni KM. The effect of integrated teaching with case based learning (CBL) in the biochemistry of undergraduate medical curriculum. J Clin Diag Res. 2010;5:3058-63.

6. Massonetto JC, Marcellini C, Assis PSR, de Toledo $\mathrm{S}$. Student responses to the introduction of casebased learning and practical activities into a theoretical obstetrics and gynecology teaching programme. BMC Medical Education. 2004;4:26.

7. Tarnvik A, Stenberg B. Suitability of the multiple case methods when applied on dermatology and infectious diseases at the clinical stage of medical education. The Internet Journal of Medical Education, 2010

8. Van Ments M. The Effective Use of Role-Play. London: Kogan.

9. Shankar PR, Dubey AK, Mishra M, Deshpande VY, Chandrasekhar TS, Shivananda PG. Student attitudes towards communication skills learning in a medical college in western Nepal. Educ Health. 2006;19:7184.

10. Shankar PR, Jha N, Bajracharya O, Shrestha R, Thapa HS.Teaching Pharmacology at a Nepalese Medical School: The Student Perspective. Australas Med J. 2010;1:14-22.

11. Dwyer FM. Strategies for Improving Visual Learning. State College, Pa: Learning Services. 1978;1-20. 
12. Kromann C B, Jensen M L, Ringsted C., The effect of testing on skills learning, Med Educ. 2008;43(1):21-7.

13. Boston C. The concept of formative assessment. Practical Assess. Res Eval. 2002;8:9.

14. Appaji AC, Kulkarni R. Multiple Choice Questions As A Teaching Learning Tool In Addition To Assessment Method NJIRM. 2012;3(4):91-5.

15. Singh Arjun. Student performance and their perception of a patient-oriented problem-solving approach with audiovisual aids in teaching pathology: a comparison with traditional lectures. Advances in Medical Education and Practice. 2011;1:9-15.

Cite this article as: Manivasakan J, Arunasolamme B. Contraception module: innovative strategies to improve students' learning. Int J Reprod Contracept Obstet Gynecol 2015;4:1489-93. 